\title{
Raman spectroscopy for grading of live osteosarcoma cells
}

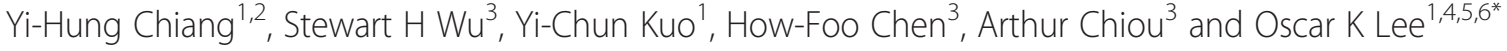

\begin{abstract}
Introduction: Osteosarcoma is the most common primary malignant bone tumor, and the grading of osteosarcoma cells relies on traditional histopathology and molecular biology methods, which require RNA extraction, protein isolation and immunohistological staining. All these methods require cell isolation, lysis or fixation, which is time-consuming and requires certain amount of tumor specimen. In this study, we report the use of Raman spectroscopy for grading of malignant osteosarcoma cells.

Methods: We demonstrate that, based on the detection of differential production of mineral species, Raman spectroscopy can be used as a live cell analyzer to accurately assess the grades of osteosarcoma cells by evaluating their mineralization levels. Mineralization level was assessed by measuring amount of hydroxyapatite (HA), which is highly expressed in mature osteoblasts, but not in poorly differentiated osteosarcoma cell or mesenchymal stem cells, the putative cell-of-origin of osteosarcoma.
\end{abstract}

Results: We found that under Raman spectroscopy, the level of HA production was high in MG-63 cells, which are low-grade. Moreover, hydroxyapatite production was low in high-grade osteosarcoma cells such as $143 \mathrm{~B}$ and SaOS2 cells $(p<0.05)$. Matrix metalloproteinase MMP2, MMP9 were highly expressed in SaOS2, 143B and MSCs and decreased in human fetal osteoblast (FOB) and MG-63 cells as expected $(p<0.05)$. These results may highlight the inverse correlation between HA level and prognosis of osteosarcoma.

Conclusions: The use of Raman spectroscopy for the measurement of HA production by the protocol reported in this study may serve as a useful tool to rapidly and accurately assess the degree of malignancy in osteosarcoma cells in a label-free manner. Such application may shorten the period of pathological diagnosis and may benefit patients who are inflicted with osteosarcoma.

\section{Introduction}

Osteosarcoma is the most common primary malignant bone tumor and is most prevalent among children and teenagers. Osteosarcoma is defined as a malignant tumor of connective tissue origin. Malignant transformation of mesenchymal stem cells (MSCs) or osteoblastic progenitor cells during bone remodeling has been reported [1-6]. Patients with nonmetastatic osteosarcoma often have a 5-year survival rate of around 60\% [7-9]. However, patients with lung metastases and poor response to chemotherapy end up with a low survival rate of $20 \%$

\footnotetext{
* Correspondence: DAV47@tpech.gov.tw

${ }^{1}$ Institute of Clinical Medicine, National Yang-Ming University, No. 155, Sec2, Linong Street, Taipei 112, Taiwan

${ }^{4}$ Department of Orthopaedic Surgery, Taipei City Hospital, No. 145,

Zhengzhou Road, Taipei 10341, Taiwan

Full list of author information is available at the end of the article
}

[2,3]. Histologic grading in osteosarcomas is therefore important in the diagnosis. For osteosarcoma, however, traditional histopathology methods are time consuming, and they can only offer semiquantitative or nonquantitative information. A sensitive and objective method for diagnosis of osteosarcoma is not readily available.

MSCs have been identified as the nonhematopoietic stem cells residing in bone marrow stoma, which have the capability of differentiation into tissues of mesodermal origin such as osteoblasts, adipocytes, chondrocytes, and tenocytes [10-13]. MSCs play an important role in normal bone formation and remodeling. Potential clinical applications of MSCs have been reported in recent years $[9,14,15]$. Osteoblasts, the progenies of MSCs, are bone-forming cells which are pivotal in homeostasis of the bone marrow microenvironment [16]. 
Raman spectroscopy has been extensively used in a wide variety of biological applications. Owing to its high sensitivity and selectivity, Raman spectroscopy has been recognized as a powerful tool and has been widely used for dynamic chemical analysis in molecular identification and drug screening [17-21]. The technique provides a detailed molecular structure, chemical composition, and molecular interaction in tissues and cells [17,18,21-23]. The molecular composition and structural characteristics in the spectra are often associated with disease severity. Hence, quantitative spectral changes specific to a particular state of disease can be sufficiently used as biomarkers [24]. Previously, we reported the differences between Raman spectra of the undifferentiated and differentiated human MSCs and demonstrated that Raman spectroscopy is an effective biosensor to monitor the production of different mineralized matrices during osteogenic differentiation of MSCs, which can be used to evaluate their maturation level of osteogenic differentiation [25]. Recently, the feasibility of using cellular Raman spectroscopic fingerprinting of cells for clinical diagnosis has been demonstrated successfully [26-28]. Importantly, MSCs have been reported as the putative cell of origin for osteosarcoma [29].

Hydroxyapatite (HA) is a natural mineral form of calcium apatite with chemical formula $\mathrm{Ca}_{10}\left(\mathrm{PO}_{4}\right)_{6}(\mathrm{OH})_{2}$. The mineral distribution increases with maturation upon osteoblast differentiation of MSCs [25]. We reason that it may be possible to use production of the HA molecule to detect the degree of malignancy of osteosarcoma cells, because it is known that the more malignant the cancer cells, the more immature they will be and the less HA these cells will produce [30].

The purpose of this study is to investigate the possibility of using Raman spectroscopy in the measurement of HA production to identify the degree of malignancy of osteosarcoma cells. In this study, we seek to compare the level of HA production of osteosarcoma cells [28,31] including SaOS2 and143B cells, which are high-grade osteosarcoma cells, and MG63 cells [32-34], which are low grade. Human MSCs and human fetal osteoblast (hFOB) cells serve as a reference for bone formation and are used as controls in this study. Our hypothesis is that osteosarcoma cells with different degrees of malignancy can be distinguished by the amount of HA production under Raman spectroscopy.

\section{Methods}

Maintenance and expansion of mesenchymal stem cells Commercially available human MSCs were purchased from Lonza (Walkersville, MD, USA). Their ability to differentiate into osteoblasts, chondrocytes, and adipocytes was confirmed. hFOB cells, the differentiated osteoblasts, were used as controls. MG63, SaOS2 and 143B cells were obtained from Sigma-Aldrich (St. Louis, MO, USA). As adherent cells reached approximately 50 to $70 \%$ confluence, they were detached with $0.25 \%$ trypsin-ethylenediamine tetraacetic acid (Gibco, Grand Island, NY, USA), washed twice with phosphate-buffered saline (PBS; Sigma-Aldrich, St. Louis, MO, USA ), centrifuged under $1,000 \mathrm{rpm}(200 \times g)$ for 5 minutes, and reseeded at 1:3 under the same culture conditions.

\section{Culture medium}

Expansion medium for MSCs consists of MSC growth medium (MesenPRO; Gibco), $100 \mathrm{U}$ penicillin, 1,000 U streptomycin, and $2 \mathrm{mML}$-glutamine (Gibco). Expansion medium for MG63 (osteoblast-like osteosarcoma cell line), SaOS2 and 143B (high-grade osteosarcoma cell line), and hFOB cells consists of Iscove modified Dulbecco medium (Gibco) and 10\% fetal bovine serum (Hyclone, Logan, UT, USA) supplemented with $100 \mathrm{U}$ penicillin, 1,000 U streptomycin, and $2 \mathrm{mM}$ L-glutamine (Gibco).

\section{Raman spectroscopy}

Raman spectra were equipped with a liquid-nitrogencooled detector. An $80 \mathrm{~cm}$ focal length spectrometer system (HR800; Jobin Yvon, Longjumeau Cedex, France) was used in this study with a $1,800 \mathrm{~g} / \mathrm{mm}$ holographic grating to provide a spectral resolution of $1 \mathrm{~cm}^{-1}$. Spectra were recorded from 800 to $3,500 \mathrm{~cm}^{-1}$ with a resolution of approximately $5 \mathrm{~cm}^{-1}$.

MSCs were seeded on a $2 \mathrm{~mm} \times 2 \mathrm{~mm}$ quartz coverslip and treated with osteogenic induction medium consisting of $10 \mathrm{mM} \beta$-glycerophosphate, $0.2 \mathrm{mM}$ ascorbic acid, and $0.1 \mu \mathrm{m}$ dexamethasone. Before measurement, cells were twice washed with PBS, and the coverslip was placed on a quartz slide. An O-ring was placed between the coverslip and the slide. The minimized chamber was filled with PBS to prevent cell death during the measurement.

Each Raman spectrum represented the average of five different replicates on one single cell surface. Labspec 5.0 software (HORIBA Scientific, Ediso, NJ, USA) was used for signal processing. All spectra in this study were normalized to $\mathrm{CH}_{2}$ wag at $1,449 \mathrm{~cm}^{-1}$.

The signal from extracellular matrix protein was measured from each spectrum, which facilitates calculation of the mineral-to-matrix ratio to indicate the relative level of mineralization in the extracellular matrix [35]. Phenylalanine, which is ubiquitously present within all extracellular matrices and with a background spectrum at $1,004 \mathrm{~cm}^{-1}$, was used for calculation of the mineralto-matrix ratio of the substrates [36,37]. The band area intensity for $\mathrm{HA}$ in the cells was normalized against phenylalanine before averaging [23]. 


\section{Histochemical staining of hydroxyapatite}

To evaluate the production of HA, cells were rinsed twice with PBS, fixed with $3.7 \%$ formaldehyde for $20 \mathrm{mi}$ nutes, and washed with distilled water. The mineralization matrix was analyzed with Von kossa staining using 1\% silver nitrate (Sigma-Aldrich) under UV light for 45 minutes, followed by $3 \%$ sodium thiosulfate (Sigma-Aldrich) for 5 minutes, and then counterstained with van Gieson (Sigma-Aldrich) for 5 minutes. The cultures were then stained for 45 minutes with $2 \%$ Alizarin red $\mathrm{S}$ at room temperature with shaking. Alizarin red S, a dye that stains calcium salts selectively and is widely used for mineral histochemistry of calcium, served to analyze the mineralization level of cells. The cultures were washed three times with water after staining. Stained cultures were photographed using an inverted microscope.

\section{Quantitative real-time PCR analysis}

RNA was prepared from $3 \times 10^{5}$ in vitro culture cells, including human MSCs, hFOBs, and MG63, and total RNA was isolated using Trizol (Invitrogen, Grand Island, NY, USA) and cleaned using an RNA easy minikit (Quiagen, Courtaboeuf, France). We reverse transcribed the messenger RNA to complementary DNA using reagents (Genemark Technology, Taipei, Taiwan) according to the manufacturer's instructions. Quantitative real-time PCR analysis of total RNA from cultured cells was performed using the ABI Step One Plus Real Time PCR System (Applied Biosystems, Foster City, California, USA). cDNA was amplified using an ABI Step One Plus Real Time PCR System at $95^{\circ} \mathrm{C}$ for 60 seconds, $56^{\circ} \mathrm{C}$ for 45 seconds, and $72^{\circ} \mathrm{C}$ for 60 seconds for 40 cycles, after initial denaturation at $95^{\circ} \mathrm{C}$ for 5 minutes. The primers used for amplification were: matrix metalloproteinase (MMP)2, forward 5'-TGAAGCACAGCAGGTCTCAG-3' and reverse 5'-GTGTTCAAACCAGGCACCTC-3'; MMP9, forward 5' -GAACCAATCTCACCGACAGG-3' and reverse 5'-GCCACCCGAGTGTAACCATA-3'; extracellular matrix metalloproteinase inducer (EMMPRIN), forward 5 '-GAAT GACAGCGCCACAGAG-3' and reverse 5' -TACTCTCCC CACTGGTCGTC-3'; osteocalcin, forward 5'-TGAGAGC CCTCACACTCCTC-3' and reverse $5^{\prime}$-ACCTTTGCTGG ACTCTGCAC-3'; and glyceraldehyde 3-phosphate dehydrogenase, forward 5'-AGCCACATCGCTCAGACAC$3^{\prime}$ and reverse $5^{\prime}$-GCCCAATACGACCAAATCC-3'.

\section{Data analysis}

Statistical analyses were performed by Student's $t$ test for two groups of data and by one-way analysis of variance with post hoc tests for multiple comparisons. Data were expressed as mean \pm standard error of the mean from three independent experiments and $P<0.05$ was considered statistically significant.

\section{Results}

\section{Setup of Raman spectroscopy}

Cells were seeded on a $2 \mathrm{~mm} \times 2 \mathrm{~mm}$ quartz coverslip and then were placed on a quartz slide. An O-ring was placed between the coverslip and the slide. In this study, an $18 \mathrm{~mW} \mathrm{He}-\mathrm{Ne}$ laser operating at $632.8 \mathrm{~nm}$ was used to provide the Raman excitation and the excitation beam traveled through the Neutral density filter and interference filter in order to block unwanted light and to transmit the desired wavelength. The laser power $(18 \mathrm{~mW}$ full-beam power at the sample) was adjusted to attain a sufficient signal-to-noise ratio and to avoid sample damage. The selected laser beam then stimulated Raman effects in the sample on the quartz. For Raman spectroscopic imaging, a confocal Raman microscope (BX-41; Olympus, Shinjuku, Tokyo, Japan) was used with a $60 \times$ water immersion $\mathrm{M}-\mathrm{Plan}$ objective $(\mathrm{NA}=0.9)$. The objective had a $2 \mathrm{~mm}$ working distance to ensure minimum invasion of the cells. The spatial resolution was about 1 to $2 \mu \mathrm{m}$ for a 1 to $2 \mu \mathrm{m}$ laser spot size. A liquid-nitrogencooled, charge-coupled, two-dimensional array detector was used to measure the Raman signal by integrating for 180 seconds. Spectra were recorded from 800 to $3,500 \mathrm{~cm}$ ${ }^{-1}$ with a resolution of approximately $5 \mathrm{~cm}^{-1}$. A schematic diagram of the Raman spectroscopy setup is shown in Figure 1.

\section{Maintenance of cells}

The five different cell lines (MSC, hFOB, MG63, SaOS2, and 143B) were well maintained in culture with proper medium. The morphology of cells was observed under an optical microscope with a $10 \times$ objective 72 hours after seeding. These cells were indistinguishable in their morphology, including shape, density, and cell-cell contact. Representative photomicrographs showing the morphology of these cells are shown in Figure 2.

\section{Raman spectrum of different osteosarcoma cells}

Raman spectra of the cells were measured and the results are shown in Figure 3A. The spectra were obtained by averaging over different locations on the cell surface with a 180-second integration time and each band envelope baseline was subtracted. Among the five cell lines, a dramatic difference was observed in the intensity of their peaks around $960 \mathrm{~cm}^{-1}$, which is dominated by the symmetric stretching of phosphate groups (Figure 3A,B). The band assignments for HA were confirmed by measuring the chemical powder of HA, as shown in Figure 3C. HA was highly expressed in mature osteoblasts and MG63 cells, which are low-grade osteoblast-like osteosarcoma. On the contrary, HA production was low in MSCs and highly malignant osteosarcoma cells ( $\mathrm{SaOS} 2$ and 143B). Raman peak intensity around $960 \mathrm{~cm}^{-1}$ is a direct indication of the level of HA in these cells. 


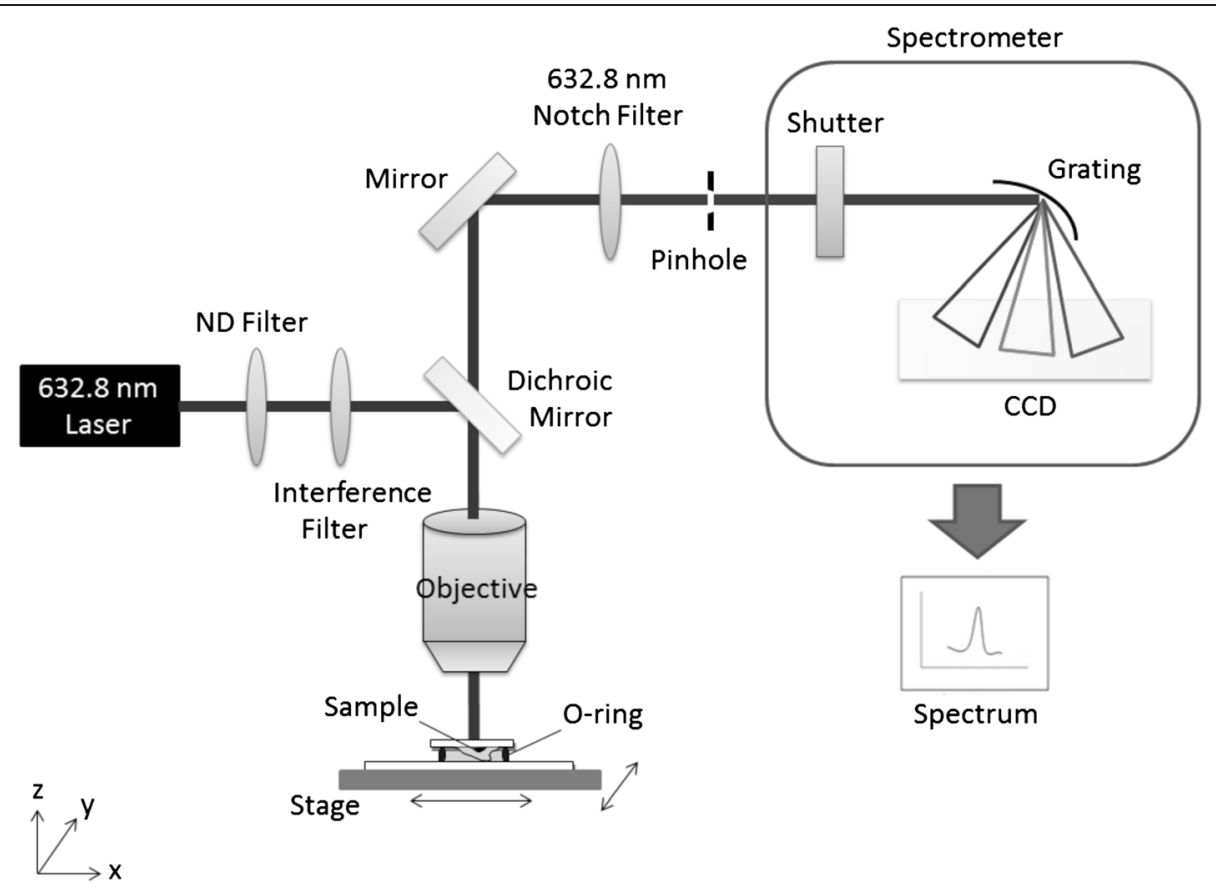

Figure 1 Schematic diagram of the Raman platform setup. CCD, charge-coupled device; ND, neutral density filter.

\section{Conventional biology assays for mineralization level of different cell lines}

To validate the results from the Raman spectroscopy method, Alizarin red S staining and von Kossa staining were used to evaluate the extent of mineralization. Alizarin is an organic compound that could react with calcium ions. The Alizarin red staining results (Figure $4 \mathrm{~A}, \mathrm{~B}$ ) clearly revealed that more calcium mineralization spots appeared in MG63 and hFOB cells than in hMSCs and SaOS2 and 143B cells. To quantify the calcium secretion level, the mineralization spots were extracted by $10 \%$ cetylpyridinium chloride, and the absorbance (at $570 \mathrm{~nm}$ ) of the clear red extracts was measured; relative intensity of HA was high in
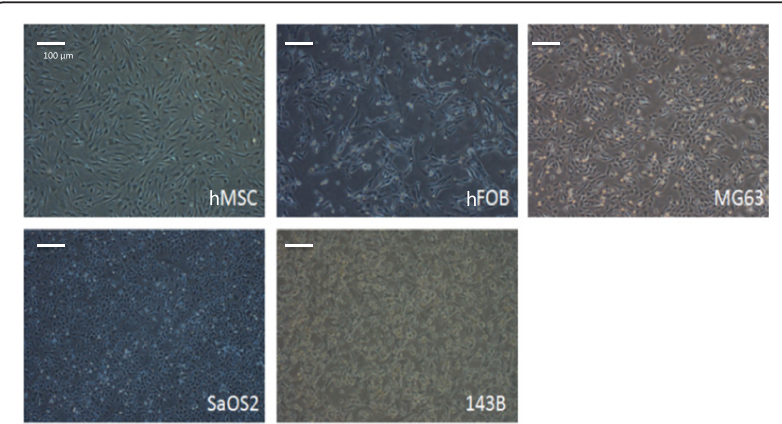

Figure 2 Morphology of different osteosarcoma cells. Morphology of human bone marrow-derived mesenchymal stem cells (hMSC), human fetal osteoblast (hFOB) cells, and osteosarcoma (MG63, SaOS2, and 143B) cells, at 80\% confluence, under a light microscope. Magnification: $10 \times$.
hFOB and MG63 cells with statistical significance. The result is shown in Figure 4C.

The von Kossa stain (Figure 4D) showed similar features, and the results were consistent with those of the Alizarin red staining. A careful comparison of the results obtained by Raman spectroscopy with those obtained by conventional biochemical methods showed that the mineralization level obtained by the Alizarin red stain and Von Kossa stain in the culture dish did match with those obtained by Raman spectroscopy, especially the quantification of Alizarin red S stain.

\section{Correlation between malignancy grading and osteogenic maturation}

Real-time PCR analysis was performed to measure the osteocalcin gene expression level in these cells and the results are shown in Figure 5. Expression of osteocalcin was high in osteoblasts (hFOB cells) and low-grade osteosarcoma cells (MG63 cells). However, in undifferentiated MSCs and more malignant osteosarcoma cells such as SaOS2 and 143B, expression of osteocalcin was significantly lower.

MMP2, MMP9, and EMMPRIN are members of the MMP protein family and are involved in breakdown of the extracellular matrix in normal physiological processes, such as reproduction, embryonic development, and tissue remodeling, as well as in disease processes, such as arthritis and metastasis [38]. MMP2, MMP9, and EMMPRIN were highly expressed in SaOS2 and $143 \mathrm{~B}$ cells and MSCs, and were decreased in hFOB and 


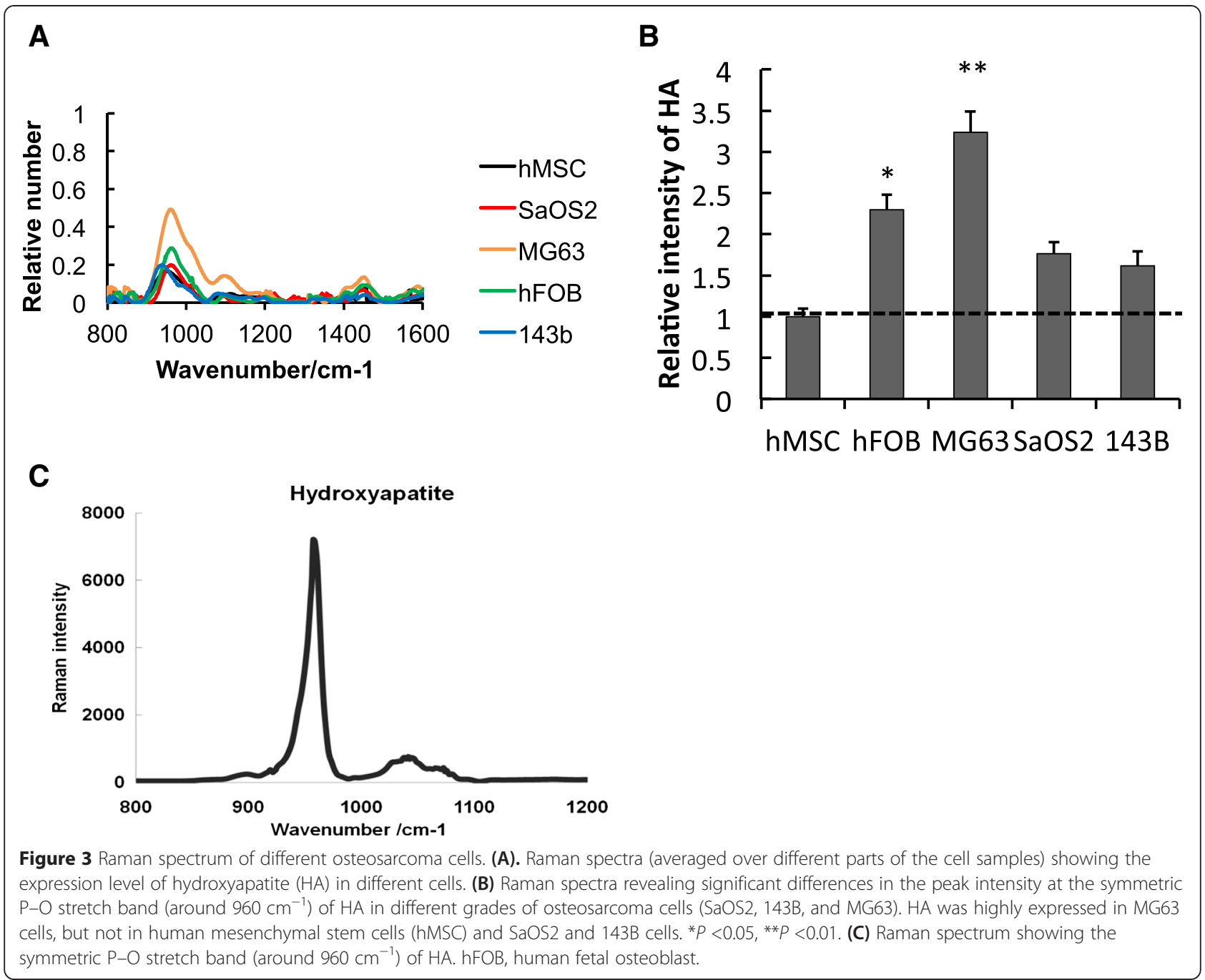

MG63 cells as expected; the levels of MMP2 and MMP9 showed statistical significance (Figure 5).

\section{Discussion}

In this study, we demonstrate that Raman spectroscopy unequivocally distinguishes the grade of malignancy of osteosarcoma cells. Traditionally, the grading usually depends on histopathology and sometimes can be difficult. Since Raman spectroscopy provides detailed information on molecular structures, the observed spectrum at a $960 \mathrm{~cm}^{-1}$ peak reveals difference among different osteosarcoma cell lines, which has not been reported elsewhere.

The $960 \mathrm{~cm}^{-1}$ peak indicates that HA and the levels of HA are believed to be related to maturation of osteogenic differentiation. To evaluate the maturation of osteogenic differentiation, histochemical and molecular biological methods such as Alizarin red staining, von kossa staining, western blot, and RT-PCR are commonly used [39-41]. The drawback is that these assays are time consuming and detection on live cells is not possible.
Previously, we have successfully developed a Raman spectroscopy-based measurement to evaluate the maturation of cells during osteogenic differentiation of MSCs and osteoblasts [25]. In this study, we further demonstrate that a similar approach can be adopted in the grading of osteosarcoma cells.

In this study, Raman spectroscopy successfully indicates the level of HA in each cell, and the RT-PCR data indicate that MMP2, MMP9, and EMMPRIN are expressed at a high level in cells with a high level of HA production. In the literature, it is reported that upregulated expression of P53, MMP, and EMMPRIN is correlated with poor prognosis in patients with osteosarcoma $[38,42]$. These results may highlight the inverse correlation between the HA level and prognosis of osteosarcoma.

It is apparent that conventional biochemical methods including staining and RT-PCR can distinguish different grades of osteosarcoma cells by measuring the mineralization level. However, all of these biochemical methods need cell fixation and/or cell lysis is 

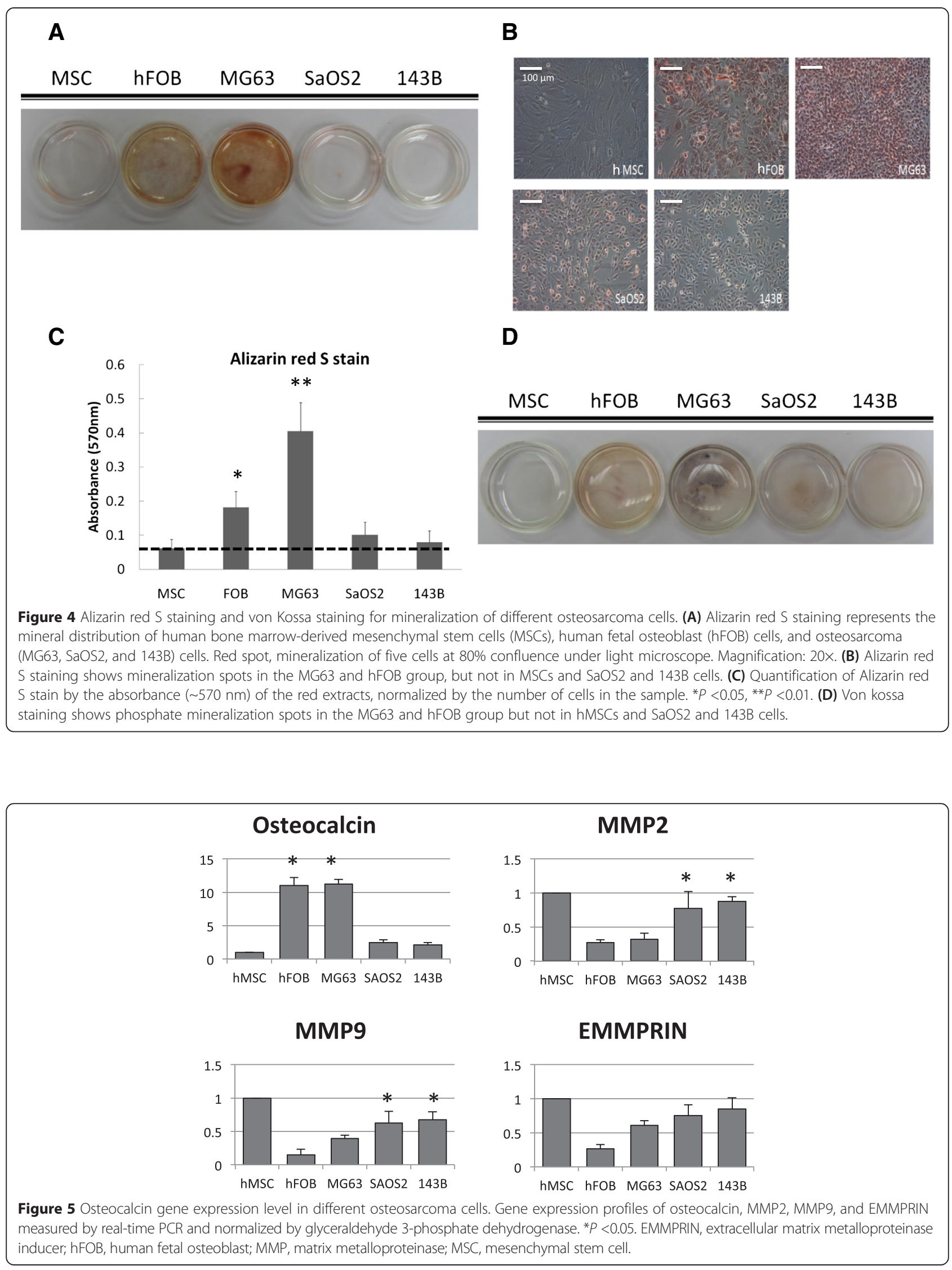
necessary. Also, the significance of histological grading is limited by interobserver variability, in addition to the fact that the majority of tumors fall into the intermediate range, which is not easy to assess quantitatively. Raman spectroscopy has been used for clinical diagnosis of many malignant diseases including breast cancer [43], lung cancer [44], and skin cancer [45]. In this study, we also unequivocally demonstrate that Raman spectroscopy can serve as a viable real-time, quantitative, in situ biodetector for osteosarcoma. Our results indicated that the Raman spectroscopy technique has a high sensitivity, is easier to use to quantitatively measure the mineralization level of cells, and is more efficient than the conventional methods. Most importantly, detection via Raman spectroscopy can potentially be achieved even with a small amount of cells. From this study we advance the possibility of using Raman spectroscopy to distinguish between high-grade and lowgrade osteosarcoma. The technique may theoretically therefore be further utilized in the diagnosis of other sarcomas. Taken together, the use of Raman spectroscopy may effectively facilitate the pathological diagnosis and malignancy grading of osteosarcoma.

We launched this study on the basis of cells but not tissues because Raman spectroscopy has the advantage of subcellular observation. The excited shorter wavelengths can enable subcellular resolution and extracellular water content can strongly absorb the emitted infrared light. Consequently, Raman spectroscopy can provide useful information on the molecular composition of cells. However, there are some limitations to our current Raman technique including the scan area, signal of Raman scattering, measurement conditions, and penetration depth. The scattering efficiency is quite low. The acquisition time from the cell takes several seconds, but it may take several hours to check live tissue. We are now trying to incorporate more powerful optical techniques such as surface-enhanced Raman scattering and coherent anti-Stokes Raman scattering to complement the deficits. Both techniques can amplify weak Raman signals and may complete the information for live human tissues in a much shorter time frame with greater sensitivity and accuracy. Our findings in this study can be further applied to research under surface-enhanced Raman scattering or coherent anti-Stokes Raman scattering. The level of HA can be interpreted as the level of mineralization and can be used as a label to grade the malignancy of osteosarcoma tissues. It is also possible that other biomarkers will be identified by surface-enhanced Raman scattering or coherent anti-Stokes Raman scattering. Further validation in clinical samples is warranted.

\section{Conclusion}

Raman spectroscopy provides a precise, sensitive, and quantitative way to distinguish different grades of osteosarcoma. By targeting HA, Raman spectroscopy provides real-time and quantitative information for clinical diagnosis. This approach for the characterization of osteosarcoma cells may substantially shorten the time required for pathological diagnosis, and patients with osteosarcoma may benefit from such rapid diagnosis.

\section{Abbreviations}

EMMPRIN: extracellular matrix metalloproteinase inducer; HA: hydroxyapatite; hFOB: human fetal osteoblast; MMP: matrix metalloproteinase; MSC: mesenchymal stem cell; PBS: phosphate-buffered saline.

\section{Competing interests}

The authors declare that they have no competing interests.

\section{Authors' contributions}

Y-HC carried out all cell culture, PCR, and statistical analyses and drafted the manuscript. SHW participated in the setup of Raman spectroscopy. Y-CK participated in the setup of Raman spectroscopy, data collection, and statistical analyses. H-FC and AETC participated in the design of the study and helped to draft the manuscript. OKL conceived of the study and participated in its design and coordination, and helped to draft the manuscript. All authors read and approved the final manuscript.

\section{Acknowledgements}

This work was supported in part by the UST-UCSD International Center of Excellence in Advanced Bio-engineering sponsored by the Taiwan Ministry of Science and Technology I-RiCE Program under grant number NSC102-2911-I009-101. The authors also acknowledge financial support from the Taipei Veterans General Hospital (VGH103E1-003, VGH103C-113), the Ministry of Science and Technology, Taiwan (NSC102-2120-M-010-001, NSC100-2314-B010-030-MY3, and NSC102-2321-B-010-008), and the Ministry of Economic Affairs, Taiwan (102-EC-17-A-17-S1-203). This study was also supported by a grant from the Ministry of Education, Aiming for the Top University Plan. The authors also thank the Medical Science \& Technology Building of Taipei Veterans General Hospital for providing experimental space and facilities.

\section{Author details}

'Institute of Clinical Medicine, National Yang-Ming University, No. 155, Sec2, Linong Street, Taipei 112, Taiwan. ${ }^{2}$ Department of Orthopaedics, National Yang-Ming University Hospital, No. 152, Xinmin Road, Yi-Lan 260, Taiwan. ${ }^{3}$ Institute of Biophotonics, National Yang-Ming University, No. 155, Sec2, Linong Street, Taipei 112, Taiwan. ${ }^{4}$ Department of Orthopaedic Surgery, Taipei City Hospital, No. 145, Zhengzhou Road, Taipei 10341, Taiwan. ${ }^{5}$ Stem Cell Research Center, National Yang-Ming University, No. 155, Sec2, Linong Street, Taipei 112, Taiwan. ${ }^{6}$ Department of Medical Research, Taipei Veterans General Hospital, No. 201, Sec 2, Shipai Road, Taipei 11217, Taiwan.

Received: 9 November 2014 Revised: 28 February 2015 Accepted: 8 April 2015 Published online: 18 April 2015

\section{References}

1. Rubio D, Garcia-Castro J, Martin MC, de la Fuente R, Cigudosa JC, Lloyd AC. Spontaneous human adult stem cell transformation. Cancer Res. 2005;65:3035-9.

2. Chou AJ, Gorlick R. Chemotherapy resistance in osteosarcoma: current challenges and future directions. Expert Rev Anticancer Ther J Raman Spectrosc. 2006;6:1075-85.

3. Miura M, Miura Y, Padilla-Nash HM, Molinolo AA, Fu B, Patel V, et al. Accumulated chromosomal instability in murine bone marrow mesenchymal stem cells leads to malignant transformation. Stem Cells. 2006;24:1095-103.

4. Aguilar S, Nye E, Chan J, Loebinger M, Spencer-Dene B, Fisk N, et al. Murine but not human mesenchymal stem cells generate osteosarcoma-like lesions in the lung. Stem Cells. 2007;25:1586-94.

5. Tolar J, Nauta AJ, Osborn MJ, Panoskaltsis Mortari A, McElmurry RT, Bell S, et al. Sarcoma derived from cultured mesenchymal stem cells. Stem Cells. 2007;25:371-9.

6. Rubio D, Garcia S, Paz MF, De la Cueva T, Lopez-Fernandez LA, Lloyd AC, et al. Molecular characterization of spontaneous mesenchymal stem cell transformation. PLoS One. 2008;3, e1398. 
7. Rebulla P, Giordano R. Regulation of cell based medicine. The European experience. The case of mesenchymal stem cell production for clinical applications. Vox Sang. 2010;99:69-70.

8. Mazzini L, Ferrero I, Luparello V, Rustichelli D, Gunetti M, Mareschi K, et al. Mesenchymal stem cell transplantation in amyotrophic lateral sclerosis: a phase I clinical trial. Exp Neurol. 2010;223:229-37.

9. Nagaya N, Ohgushi H, Shimizu W, Yamagishi M, Noguchi T, Noda T, et al. Clinical trial of autologous bone marrow mesenchymal stem cell transplantation for severe chronic heart failure. Circulation. 2007;116:453-3.

10. Pereira RF, Halford KW, O'Hara MD, Leeper DB, Sokolov BP, Pollard MD, et al. Cultured adherent cells from marrow can serve as long-lasting precursor cells for bone, cartilage, and lung in irradiated mice. Proc Natl Acad Sci U S A. 1995:92:4857-61.

11. Horwitz EM, Prockop DJ, Fitzpatrick LA, Koo WW, Gordon PL, Neel M, et al. Transplantability and therapeutic effects of bone marrow-derived mesenchymal cells in children with osteogenesis imperfecta. Nat Med. 1999:5:309-13.

12. Pittenger MF, Mackay AM, Beck SC, Jaiswal RK, Douglas R, Mosca JD, et al. Multilineage potential of adult human mesenchymal stem cells. Science. 1999;284:143-7.

13. Jiang $Y$, Jahagirdar BN, Reinhardt RL, Schwartz RE, Keene CD, Ortiz-Gonzalez $X R$, et al. Pluripotency of mesenchymal stem cells derived from adult marrow. Nature. 2002;418:41-9.

14. Swart JF, Backer MJG, Hofhuis F, Prakken BJ, Kuis W, Martens ACM, et al. Mesenchymal stem cell therapy has significant clinical effect in arthritis. Semin Arthritis Rheum. 2008;58:S263-4.

15. Brooke G, Rossetti T, llic N, Murray P, Hancock S, Pelekanos R, et al. Points to consider in designing mesenchymal stem cell-based clinical trials. Transfus Med Hemother. 2008;35:279-85

16. Calvi LM, Adams GB, Weibrecht KW, Weber JM, Olson DP, Knight MC, et al. Osteoblastic cells regulate the haematopoietic stem cell niche. Nature. 2003:425:841-6.

17. Gough JE, Notingher I, Hench LL. Osteoblast attachment and mineralized nodule formation on rough and smooth $45 \mathrm{~S} 5$ bioactive glass monoliths. J Biomed Mater Res A. 2004;68:640-50.

18. Notingher I, Jell G, Lohbauer U, Salih V, Hench LL. In situ non-invasive spectral discrimination between bone cell phenotypes used in tissue engineering. J Cell Biochem. 2004;92:1180-92.

19. Patel IS, Premasiri WR, Moir DT, Ziegler LD. Barcoding bacterial cells: a SERS-based methodology for pathogen identification. J Raman Spectrosc. 2008;39:1660-72

20. Gupta K, Kim DH, Ellison D, Smith C, Kundu A, Tuan J, et al. Lab-on-a-chip devices as an emerging platform for stem cell biology. Lab Chip. 2010;10:2019-31

21. Schulze HG, Konorov SO, Caron NJ, Piret JM, Blades MW, Turner RFB. Assessing differentiation status of human embryonic stem cells noninvasively using Raman microspectroscopy. Anal Chem. 2010;82:5020-7.

22. Notingher I, Bisson I, Bishop AE, Randle WL, Polak JM, Hench LL. In situ spectral monitoring of mRNA translation in embryonic stem cells during differentiation in vitro. Anal Chem. 2004;76:3185-93.

23. Chiang HK, Peng FY, Hung SC, Feng YC. In situ Raman spectroscopic monitoring of hydroxyapatite as human mesenchymal stem cells differentiate into osteoblasts. J Raman Spectrosc. 2009;40:546-9.

24. Neugebauer U, Bocklitz T, Clement JH, Krafft C, Popp J. Towards detection and identification of circulating tumour cells using Raman spectroscopy. Analyst. 2010;135:3178-82.

25. Hung PS, Kuo YC, Chen HG, Chiang HH, Lee OK. Detection of osteogenic differentiation by differential mineralized matrix production in mesenchymal stromal cells by Raman spectroscopy. PLoS One. 2013:8, e65438.

26. Yu G, Lu AJ, Wang B, Zhang CZ. Raman imaging based on morphological model for human breast cancer tissues. Guang Pu Xue Yu Guang Pu Fen Xi. 2010;30:2167-70

27. Karl A, Tritschler S, Zaak D, Tilki D, Stief C, Burger M. Diagnostic procedure for bladder cancer. Standards and current developments. Urologe A. 2010;49:1303-11. quiz 1312.

28. Eppert K, Wunder JS, Aneliunas V, Kandel R, Andrulis IL. von Willebrand factor expression in osteosarcoma metastasis. Mod Pathol. 2005;18:388-97.

29. Mutsaers AJ, Walkley CR. Cells of origin in osteosarcoma: mesenchymal stem cells or osteoblast committed cells? Bone. 2014;62:56-63.

30. Klein MJ, Siegal GP. Osteosarcoma: anatomic and histologic variants. Am J Clin Pathol. 2006;125:555-81.
31. Murase M, Kano M, Tsukahara T, Takahashi A, Torigoe T, Kawaguchi S, et al. Side population cells have the characteristics of cancer stem-like cells/cancerinitiating cells in bone sarcomas. Br J Cancer. 2009;101:1425-32.

32. Hantusch B, Kalt R, Krieger S, Puri C, Kerjaschki D. Sp1/Sp3 and DNA-methylation contribute to basal transcriptional activation of human podoplanin in MG63 versus Saos-2 osteoblastic cells. BMC Mol Biol. 2007:8:20.

33. Rausch-fan XH, Qu Z, Wieland M, Matejka M, Schedle A. Differentiation and cytokine synthesis of human alveolar osteoblasts compared to osteoblast-like cells (MG63) in response to titanium surfaces. Dent Mater. 2008;24:102-10.

34. Pappalardo S, Mastrangelo F, Marroccia DR, Cappello V, Ciampoli C, Carlino $\checkmark$, et al. Bone regeneration: in vitro evaluation of the behaviour of osteoblast-like Mg63 cells placed in contact with polylactic-co-glycolic acid, deproteinized bovine bone and demineralized freeze-dried bone allograft. J Biol Regul Homeost Agents. 2008:22:175-83.

35. Morris MD, Mandair GS. Raman assessment of bone quality. Clin Orthop Relat Res. 2011;469:2160-9.

36. Stewart S, Shea DA, Tarnowski CP, Morris MD, Wang D, Franceschi R, et al. Trends in early mineralization of murine calvarial osteoblastic cultures: a Raman microscopic study. J Raman Spectrosc. 2002;33:536-43.

37. Tarnowski CP, Ignelzi Jr MA, Morris MD. Mineralization of developing mouse calvaria as revealed by Raman microspectroscopy. J Bone Miner Res. 2002;17:1118-26.

38. Zhou QA, Zhu Y, Deng ZS, Long HT, Zhang SX, Chen XL. VEGF and EMMPRIN expression correlates with survival of patients with osteosarcoma. Surg Oncol. 2011;20:13-9.

39. Shih YR, Chen CN, Tsai SW, Wang YJ, Lee OK. Growth of mesenchymal stem cells on electrospun type I collagen nanofibers. Stem Cells. 2006;24:2391-7.

40. Cheng MT, Yang HW, Chen TH, Lee OK. Modulation of proliferation and differentiation of human anterior cruciate ligament-derived stem cells by different growth factors. Tissue Eng Part A. 2009;15:3979-89.

41. Panetta NJ, Gupta DM, Quarto N, Longaker MT. Mesenchymal cells for skeletal tissue engineering. Panminerva Med. 2009;51:25-41.

42. Fu HL, Shao L, Wang Q, Jia T, Li M, Yang DP. A systematic review of p53 as a biomarker of survival in patients with osteosarcoma. Tumor Biol. 2013:34:3817-21

43. Ding H, Nyman JS, Sterling JA, Perrien DS, Mahadevan-Jansen A, Bi X. Development of Raman spectral markers to assess metastatic bone in breast cancer. J Biomed Opt. 2014;19:111606.

44. Kaminaka S, Ito T, Yamazaki H, Kohda E, Hamaguchi H. Near-infrared multichannel Raman spectroscopy toward real-time in vivo cancer diagnosis. J Raman Spectrosc. 2002;33:498-502.

45. Sigurdsson S, Philipsen PA, Hansen LK, Larsen J, Gniadecka M, Wulf HC. Detection of skin cancer by classification of Raman spectra. IEEE Trans Biomed Eng. 2004;51:1784-93.

\section{Submit your next manuscript to BioMed Central and take full advantage of:}

- Convenient online submission

- Thorough peer review

- No space constraints or color figure charges

- Immediate publication on acceptance

- Inclusion in PubMed, CAS, Scopus and Google Scholar

- Research which is freely available for redistribution

Submit your manuscript at www.biomedcentral.com/submit
C BioMed Central 